\title{
A DECISION SUPPORT MODEL FOR CONSTRUCTION CASH FLOW MANAGEMENT
}

\author{
F. Khosrowshahi ${ }^{1} \&$ A. Kaka ${ }^{2}$ \\ 1 School of the Built Environment, University of Salford, f.khosrowshahi@ salford.ac.uk \\ 2 School of the Built Environment, University of Edinburgh, a.p.kaka@ sbe.hw.ac.uk
}

\section{ABSTRACT}

The excessive level of construction business failures and their association with financial difficulties has placed financial management in the forefront of many business imperatives. This has highlighted the importance of cash flow forecasting and management which has given rise to the development of several forecasting models. The traditional approach to the use of project financial models has been largely project-oriented perspective. However, the dominating role of 'project economics' in shaping 'corporate economics' tends to place the corporate strategy at the mercy of the projects. This paper approaches the concept of cash flow forecasting and management from a fresh perspective. Here, the use of forecasting models is extended beyond their traditional role as a guideline for monitoring and control of progress. They are regarded as tools for driving the project in the direction of corporate goals. The work is based on the premise that the main parties could negotiate the terms 
and attempt to complement their priorities. As part of this approach, a model is proposed for forecasting and management of project cash flow. The mathematical component of the model integrates three modules: an exponential and two $4^{\text {th }}$ degree polynomials. The model generates a forecast by potentially combining the outcome of data analysis with the experience and knowledge of the forecaster/organisation. In light of corporate objectives, the generated forecast is then manipulated and replaced by a range of favourable but realistic cash flow profiles. Finally, through negotiation with other parties, a compromised favourable cash flow is achieved. This paper will describe the novel way the model is used as a decision support tool. While the structure of the model and its mathematical components are described in detail, the data processing and analysis parts are briefly described and referenced accordingly. The viability of the model and the approach are demonstrated by means of a scenario.

\section{INTRODUCTION}

The reputation of construction industry as a high-risk business is due to the high level of business failures which is far beyond those in many other industries. While these failures result from the combination of several factors, the financial-related causes account for a considerable proportion of them, manifesting themselves in low returns, losses and, in some cases, liquidations. 
To this end, construction projects remain as the core of all financial burdens. The concurrency of several projects each at a different stage exerts a considerable financial demand on the contractor. The severity of this may exceed far beyond contractor's means and capabilities, resulting in undesirable compromises the effects of which can be detrimental to the success and indeed survival of the company.

Construction businesses have long used one or more ad-hoc forms of cash flow management. However, the systematic and scientific approaches are relatively new. The vast majority of project cash flow models are based on the use of ' $S$ ' curves to forecast project expenditure flow. Initially, and for a long period, the forecast has consisted of the identification of production quantities, their multiplication by the estimated unit cost and their allocation to their respective time interval, based on a predetermined schedule.

During the 1970s, the need for cash flow management was sharply felt by businesses. The high level of interest rates gave rise to concern over the impact of cash management on the overall performance of the organisation. The degree of success and failure was largely dependent on tactical financial manipulations such as price fluctuation adjustments, negative front-end loading etc. (Ashley and Teicholz, 1977). The economic pressures and uncertainties of the 1970s intensified the surge of interest in models that produced results fast, cheap and at an early stage. Subsequently, this period was marked by the increasing use of mathematical modelling in all disciplines, which also permeated into construction industry. This resulted in the development of 
several models including Hardy (1970) examining ' $S$ ' curves of 25 different project types; Bromilow and Henderson(1974) developing value 'S' curves for four categories of project type; Keller and Ashrafi (1984) incorporating project complexity; Balkau (1975) generating a value 'S' curve model; Drake (1978) and Hudson (1978) developing polynomial models, the latter being based on data from DHSS (Department of Health and Social Security) hospital projects; Allsop (1980), and Berney and Howes (1982) focusing on standard curves; Singh and Woon (1984) producing envelopes of ' $S$ ' curves for commercial, industrial and residential buildings; Neil (1982) reviewing the impact of project organisation; Tucker (1988); Oliver (1984), and Kenley and Wilson (1986) considering each project as a unique case; Kaka and Price (1991/1993) taking further the use of Logit transfer; Lowe et al. (1993) exploiting Expert Systems to help clients manage their cash flow; Kaka and Khosrowshahi (1996) looking at the impact of procurement method on contractors' cash flow, and the use artificial neural networks to aid forecasting (Boussabaine et al., 1999).

The above studies gave rise to the development of a series of models which can be grouped into a number of categories. The main categorisation relates to whether the model is based on the use of a mathematical expression or alternative methods such as heuristic, activity-based and the use of cost centres. All these models are yet to make an impact on the industry which often tends to make use of activity-based forecasting (often derived from project management systems), elemental approach (with the use of an estimating package) or a simplified decomposition method of separating areas of cost into 
labour, material, equipment and overhead, as suggested by Harris and McCaffer (1995). This is probably due to lack of confidence about the accuracy of the forecasting models (Flanagan and Norman, 1983, and Kaka and Evans, 1998).

The benefits of mathematical models have long been recognised as being practical, simple, fast and not requiring extensive information about the project. Further, there has been no evidence of the superiority of activity or elemental based methods over the alternative mathematical methods. For the most part, the mathematically-based models tend to develop a mathematical expression that best fits the collected data (e.g. Hudson, 1978). Alternatively, some models are produced by fitting a predetermined function into the collected data (e.g. Berny and Howes, 1982 and Kaka and Price, 1993). However, in most cases the interdependence of the mathematical expression and the data inherently limits the use of the model: with the introduction of each new scenario, a new mathematical expression needs to be generated and on every occasion, the model is representative only of the data that were used for its generation. Also, in cases where data are fitted to a preset model, the resulting model is too limiting in its application, because it assumes extensive generalisation.

This paper offers a model which overcomes these limitations by separating the mathematical component of the model from its data. The model initially explores the general characteristics of construction expenditure data in order to identify the nature of the mathematical expression that is capable of simulating 
these characteristics. Subsequent to this investigation, the project characteristic data are analysed and associated with the attributes of the mathematical model. Here, while the structure of the model is described and the mathematical expressions are detailed, the data analysis stages are briefly described and referenced for further detail.

The paper approaches the concept of project financial management from a broader perspective, where projects are viewed as financial business entities that contribute towards meeting corporate objectives. Further, corporate financial objectives can be better realised through the use of models in a more deterministic way that is currently ventured. Within the context of this approach, the proposed mathematical forecasting model is initially used to generate a forecast of project cash flow which is then used as the basis for project financial management and decisions.

In the following sections, initially, the details of the proposed forecasting model are provided by describing its structure and the mathematical component. This is followed by a section about the proposed approach on how the forecasting model could be used as a decision tool for aligning project and corporate financial managements. The viability of the approach and the use of the model are then demonstrated in a scenario relating to a real School project. 


\section{THE STRUCTURE OF THE FORECASTING MODEL}

This section outlines the methodology for the broader research work that resulted in the development of the forecasting model. The development process is schematically shown in Figure 1. The development of the model has entailed separate independent stages. In this section the overall model and the steps of its development are described, and its mathematical component is explained in detail. The section relating to data processing and analysis are briefly explained and referenced. Figure 2 shows the process by which a forecast is generated.

The development of the forecasting model initially required an understanding of the behaviour of the expenditure profile of construction projects. This stage relied on the collection and analysis of data relating to the expenditure values of various construction projects. These consisted of 480 projects categorised under 21 types ranging from schools, offices, shops, churches and hospitals to factories, banks, flats and housing. In preparation for the analysis, a method was developed to smooth the data representing the profiles. This smoothing method consists of the following nine processes: (1) Fourth degree moving median. (2) Second degree moving average. (3) Fifth degree moving median. (4) Third degree moving median. (5) End point adjustment. (6) Third degree moving weighted average. (7) Calculation of residual values. (8) Repeating stages 1-7 to the residual values. (9) Superimposition of the smooth data and the residual values (Khosrowshahi and Alani, 2003). 


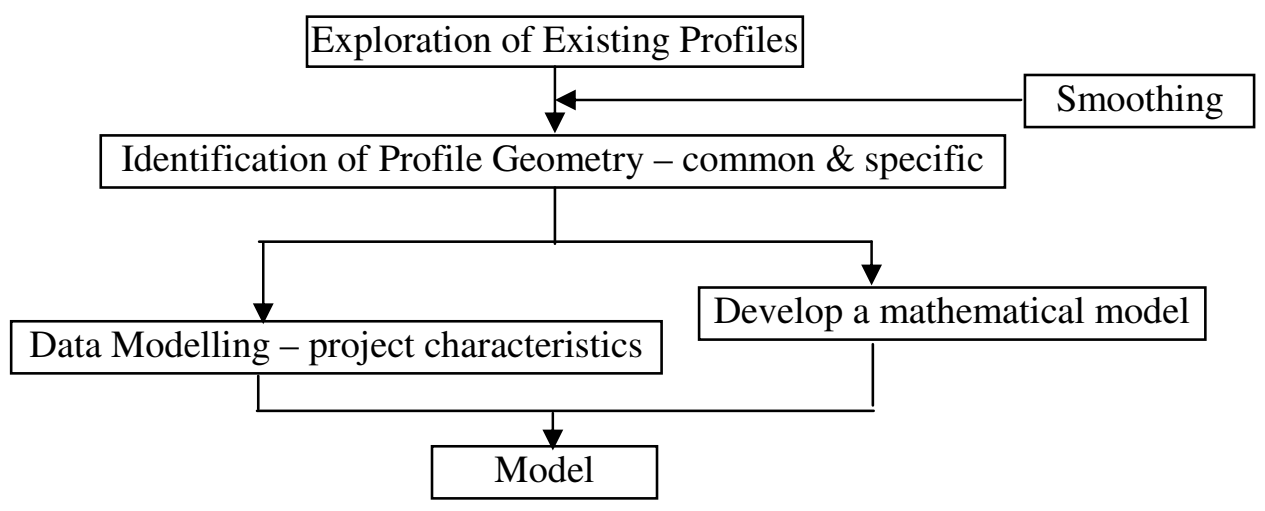

Figure 1: overview of the research methodology

The observation of the smooth profiles led to the identification of the variables that define the shape of project expenditure profile, namely profile-variables. This was then validated by applying Principal Component Analysis to these profiles. The identification of the profile-variables provided the basis for the development of the mathematical model, which incorporates these variables into its parameters.

Basically each project has a unique profile which is defined in terms of the values of its profile-variables. Once these variables are specified the mathematical component will construct the expenditure profile for that project. The final stage in the development of the overall model was to establish relationship between the profile-variables and the characteristics of each individual project. In other words, identify means by which the values of profile-variables of a given project are estimated. For this purpose, a series of estimating-models are developed which, for a given project definition, generate an estimate of the value of the profile-variables for that project. Details of these estimating-models are provided in Khosrowshahi (1996). These estimates are 
then provided to the mathematical expression and the final profile is generated. To date, there are over 78 such models for several categories of project. New estimating models can be routinely generated for new categories of project data. It is suggested that in order to improve and refine the forecast, the general experience and specific knowledge of the analyst could be applied to the forecast. These are manifested through the manipulation of the values of profile-variables.

The above components of the model are discussed below.

\begin{tabular}{|c|c|c|c|}
\hline & Estimate Profile-Variavles & Feed profile & \\
\hline $\begin{array}{l}\text { Define } \\
\text { the } \\
\text { project }\end{array}$ & $\begin{array}{l}\text { Use estimating models (Khosrowshahi 1996) } \\
\text { Optional: use experience \& knowledge }\end{array}$ & $\begin{array}{l}\text { variables into } \\
\text { mathematical } \\
\text { model }\end{array}$ & $\begin{array}{l}\text { Forecast of } \\
\text { expenditure } \\
\text { pattern }\end{array}$ \\
\hline
\end{tabular}

Figure 2. The Forecasting Process

\section{Profile-Variables}

As noted above, the first stage is the exploration of the expenditure data relating to the profile of various projects. This is carried out by assuming a geometric approach to the examination of the behaviour of the profile of expenditure pattern. The origin of the geometric approach goes back to the freehand sketch of typical ' $S$ ' curves arising from the experience of the analyst. This is followed by the introduction of more scientific techniques such as the 
three-phased curves by Cook and Jepson (1979) and later by Berny and Howes (1982).

The purpose of the use of shape/profile geometry to the analysis of the profiles is to identify the variables that define the shape of the expenditure profile. These will help to reconstruct the shape of the profile from which numerical values are extracted. In order to identify these variables, over 480 expenditure profiles were analysed. This stage of the data analysis was aided by the combination of visual assessment and a statistical technique. The observational analysis consisted of visual examination of all profiles. These observations revealed the presence of a number of variables associated with the expenditure profile. This was then validated by using Principal Component Analysis which numerically showed links between these variables and Principal Components contained within the profile data. Out of 10 Principal Components the first four explained $95.4 \%(54.9 \%+25.6 \%+10.2 \%+4.7 \%)$ of all variations within the characteristics of the shape of the profile. These variables were categorised into common and specific variables (characteristics). The common characteristics relate to the properties of growth and all profiles need to comply with these characteristics: the growth commences from the start and reaches a peak point before descending to the termination point. In doing so, the curve never experiences a negative value and the decay phase simply reflects the retarded rate of growth. Furthermore, it is expected that the curve commences from zero (start) and eventually moves towards zero (end). 
On the other hand, the specific characteristics consist of 6 variables that are likely to be different for different projects. These variables are the position of the peak on both time and value axes, the slope at the beginning and end of the expenditure curve, the intensity of expenditure from the beginning to the peak point and the attributes of any distortion on the expenditure profile. These specific characteristics are discussed below:

Peak Point Values (Xp time and Yp cost): Figures 3 and 4, show, respectively, that for different projects the time and value co-ordinates of the peak (where the rate of periodical expenditure is at the highest) can vary for different projects.

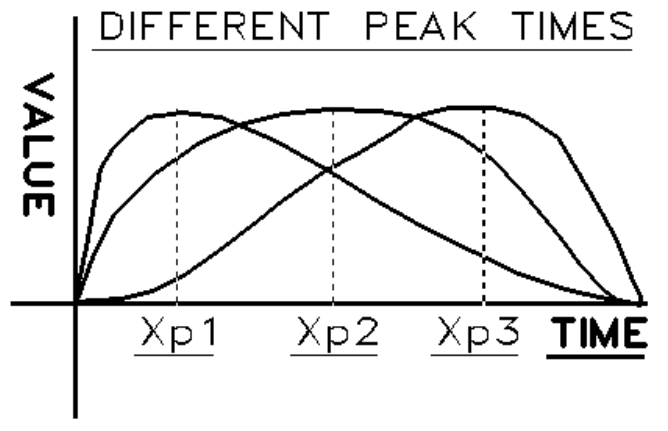

Figure 3. Varying time of peak expenditure 


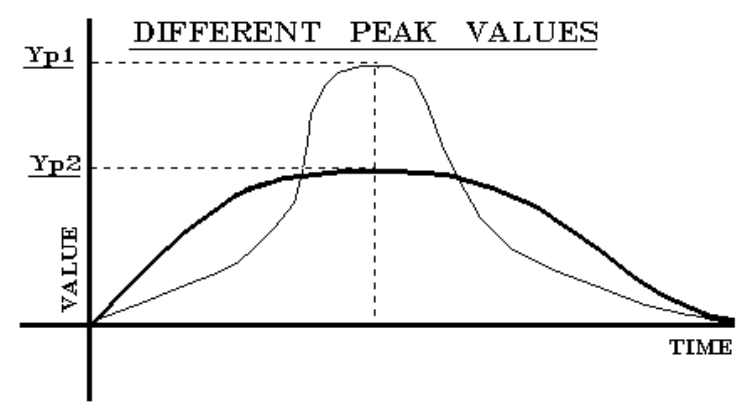

Figure 4. Varying value of peak expenditure

Slope Values (initial \& end): The slopes of the growth curve at the beginning and end of the profile were identified as another pair of specific characteristics that behave differently for different projects. Some possible variations are shown in Figure 5.

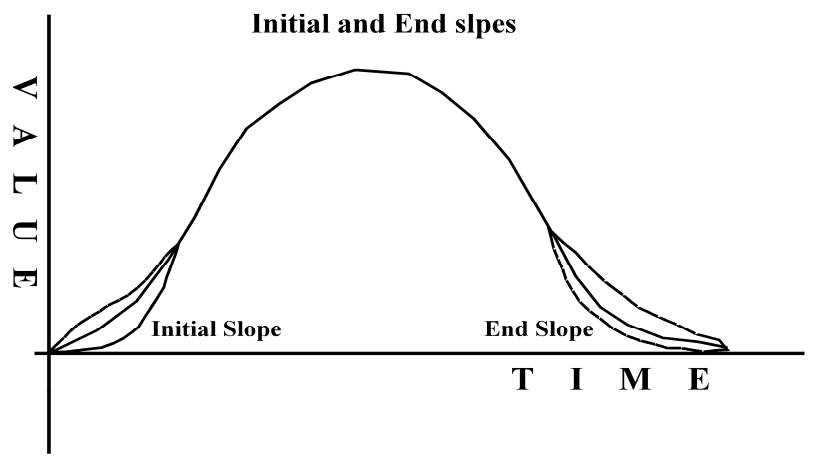

Figure 5. Initial \& End Slope Examples 
Expenditure Intensity: Another way by which the profiles of expenditure patterns are distinguished from one another is the way the cumulative expenditure is apportioned on either side of the peak point. This variable, referred to as the expenditure intensity, is closely related to the position of the peak point on the time axis. Three possibilities are shown in Figure 6.

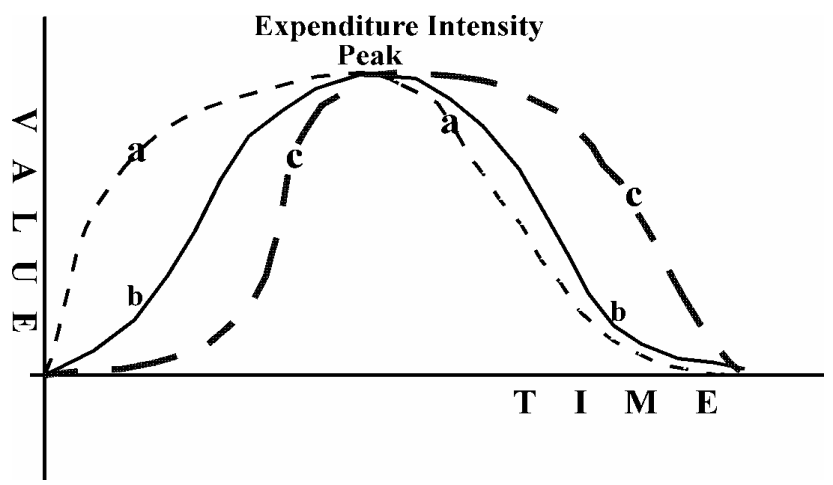

Figure 6. Examples of varying intensity

Distortions: The underlying pattern of growth is assumed to be smooth and continuous. However, often the pattern is distorted due to external abnormal events such as weather condition or sometimes due to the nature of the project. After smoothing the profiles, it became evident that they often contain up to 4 secondary peaks and troughs. These peaks and troughs are in effect distortions on the generalised pattern. A distortion is measured in terms of its position (where the trough is), duration (the distance between the encompassing peaks), intensity 
(the total sum of values distorted) and type (accelerating or retarding). Figure 7 shows the variables of a distortion.

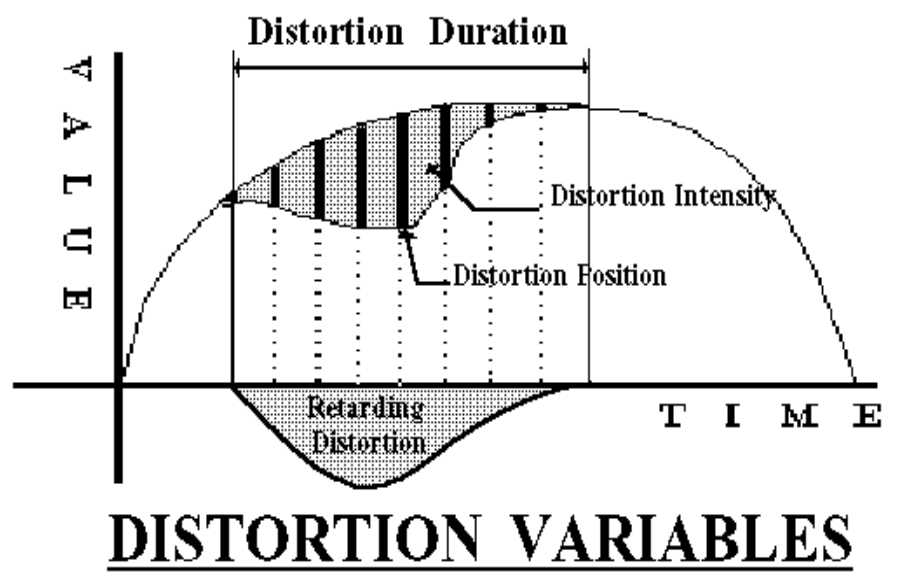

Figure 7. Variables of a Distortion

\section{Project Definition}

The periodic expenditure profile of a project can be expressed in terms of the above profile-variables. But, the identification of the value of these variables, for each specific project, required analysis of data. In order to identify the relationship between these variables and project characteristics, some 21,000 multiple regression models have been developed, using processed data relating to 480 projects comprising 21 categories of construction projects. The data consisted of two parts: numeric and descriptive. The former related to expenditure flow of each project which were then refined and smoothed. The descriptive data 
were the characteristics that defined each project. These characteristics are listed below.

1. Project type and sub-type; e.g. Advanced Factory

2. Project operation: new, rehabilitation, extension, alteration, etc.

3. Project form: architectural features: modern, standard, purpose built, etc.

4. Project scope: one-off, phased, shell, multiple, etc.

5. Structure: vertical \& horizontal load-bearing parts; steel, concrete, timber, etc.

6. General condition of the ground: good, fair or bad.

7. Access within the construction area: horizontal and vertical

8. Project size and height.

9. Buildability.

10. Abnormal events: delays, mistakes, constraints, etc.

For any project, defined broadly in terms of the above characteristics, the estimating models will predict the value of the profile-variables. The influence of each characteristic varies for each case which is determined by the significance level produced by the aforementioned regression models. The analysis that led to the development of the estimating models was a substantial piece of work the details of which are provided in Khosrowshahi (1996).

Once a forecast is generated, the analysts can use their general experience to improve the forecast. Also, they can use their knowledge about the project to further refine the forecast. Examples include familiarity with a particular subcontractor and the impact of inclement weather. The reflection of user's 
experience and knowledge is carried out through the manipulation of profilevariables. As yet, there are no set rules for influencing the profile variables after they are estimated. Basically, the team could have a meeting to discuss and use their general experience and specific knowledge of the project to manually alter the profile variables. The extent to which the team or analyst could influence the accuracy of the forecast is outside the scope of this work and in the forthcoming scenario the knowledge and experience of the analyst have not been included in the refinement of the forecast.

\section{THE MATHEMATICAL EXPRESSION}

So far it has been established that all expenditure profiles contain certain characteristics that are expressed as variables. These variables form the basis of the development of the mathematical model. The examination of several exponential expressions proved that none is suitable for the requirements of this work. However, these examinations paved the way for the development of a new expression. The resulting mathematical expression consisted of three separate modules: Control module, Kurtosis module and Distortion module. These modules are expected to behave independently, however, when combined, they should comply with all the aforementioned general and specific requirements. In order to achieve this, it is imperative that the parameters of the expression are fully interpretable. 


\section{The Control Module}

Due to its direct association with the properties of growth, the control module is expected to be of exponential nature (Gompertz, 1825 and Stone, 1980). While complying with the general properties of growth, this module should facilitate full control over the position of the peak on both the time and value axes. The curve produced by this module should have zero initial and end slopes so as not to interfere with other modules. Also, this module is responsible for controlling the overall area under the curve which reflects the total project sum. The requirement for the growth properties suggested that the module should be based on an exponential curve which satisfies the following requirements:

$$
\begin{array}{ll}
f(0)=0 \& f(1)=0 & \text { zero values at the start and end of project } \\
f^{\prime}(0)=0 \& f^{\prime}(1)=0 & \text { zero slopes at the beginning and end }
\end{array}
$$

There is a need for three parameters to control coordinates of the peak value $\left(\mathrm{X}_{\mathrm{p}}, \mathrm{Y}_{\mathrm{p}}\right)$ and the area under the curve. The expression for this module is:

$$
Y_{c}=e^{b x^{a}(1-x)^{d}}-1
$$

$\boldsymbol{Y}_{\mathbf{c}}$ represents the periodic value as a proportion of unity $\boldsymbol{x}$ is the proportion of period no. over the no. of periods 
The position of the peak on the time and cost axes are determined by $\mathrm{X}_{\mathrm{p}}$ and $\mathrm{Y}_{\mathrm{p}}$ respectively, as follows:

$$
x_{p}=\frac{a}{a+d} \quad Y_{p}=e^{b X_{p}^{a}\left(1-X_{p}\right)^{d}}-1
$$

Parameterisation of $a$ and $b$ in terms of $X_{\mathrm{p}}$ and $Y_{\mathrm{p}}$ yields the following equations;

$$
a=\frac{d X_{p}}{1-X_{p}}
$$

$$
b=\frac{L o g\left(1+Y_{p}\right)}{X_{p}^{a}\left(1-X_{p}\right)^{d}}
$$

Parameter $d$ is evaluated by the use of numerical methods. Here, iteration method is used to narrow down to the exact value for parameter $d$.

\section{The Kurtosis Module}

It was earlier noted that the mathematical expression should have full control on the values of the initial and end slopes and the value of curve-intensity. This control is carried out through the Kurtosis module which is implemented by a $4^{\text {th }}$ degree polynomial expression. In order to maintain control over the behaviour of the polynomial expression, it was decided to break the module 
into two parts: one starting from the origin to the peak point and other reversing from the end to the peak point. Since there are five conditions, the degree of polynomial is selected to be 4 , as follows:

$Y_{k}=k(X)=a_{1} X^{4}+a_{2} X^{3}+a_{3} X^{2}+a_{4} X^{1}+a_{5}$

$Y_{k}:$ the periodic values for kurtosis

$X$ : proportion of period number over kurtosis periods (origin to $X_{p} /$ end to $X_{p}$ )

The application of the constraints to the above equation provides the solution for the parameters as follows:

$\mathrm{a}_{5}=0$

$\mathrm{a}_{4}=\mathrm{g}$ (initial/end slope)

$a_{3}=[h+g(3 M-2 N-K)] /(N+L-2 M)$

$\mathrm{a}_{2}=-\left(2 \mathrm{a}_{3}+3 \mathrm{~g}\right)$

$a_{1}=-\left(g+a_{3}+a_{2}\right)$

Where

$$
\begin{aligned}
& \mathrm{N}=\mathrm{X}_{1}{ }^{4}+\mathrm{X}_{2}{ }^{4}+\mathrm{X}_{3}{ }^{4}+\ldots \mathrm{X}_{\mathrm{n}}{ }^{4} \\
& \mathrm{M}=\mathrm{X}_{1}{ }^{3}+\mathrm{X}_{2}{ }^{3}+\mathrm{X}_{3}{ }^{3}+\ldots \mathrm{X}_{\mathrm{n}}{ }^{3} \\
& \mathrm{~L}=\mathrm{X}_{1}{ }^{2}+\mathrm{X}_{2}{ }^{2}+\mathrm{X}_{3}{ }^{2}+\ldots \mathrm{X}_{\mathrm{n}}{ }^{2} \\
& \mathrm{~K}=\mathrm{X}_{1}{ }^{1}+\mathrm{X}_{2}{ }^{1}+\mathrm{X}_{3}{ }^{1}+\ldots \mathrm{X}_{\mathrm{n}}{ }^{1}
\end{aligned}
$$


Therefore, the slope is identified by $g$ and generated by the expression. As far as the curve intensity $h$ is concerned, it is calculated as follows:

$$
\sum_{i=0}^{i=X p} Y_{i}=h=N a_{1}+M a_{2}+L a_{3}+K a_{4}+
$$

Here, a percentile system is used to group slopes into 'extremely low', 'low', 'moderate', 'high, 'very high' and 'extremely high'

\section{The Distortion Module}

The Distortion module is responsible for simulating the effect of distortions on the expenditure profile. This is implemented through control over the values of the distortion parameters, namely, the position (where the trough is created), duration (distance between the two consecutive peaks encompassing the trough), intensity (the amount by which the curve is displaced) and type (accelerating or retarding the flow). Similar to the case of the Kurtosis module, the expression is a $4^{\text {th }}$ degree polynomial, but different constrains apply.

$\mathrm{d}(0)=0$ zero initial state

$\mathrm{d}(1)=0$ zero end state

$\mathrm{d}^{\prime}(0)=0$ zero initial slope

$\mathrm{d}^{\prime}(1)=0$ zero end slope

(slopes are maintained at zero, so as not to interfere with the kurtosis module) 
$Y d=d(x)=a_{1} X^{1}+a_{2} X^{2}+a_{3} X^{3}+a_{4} X^{4}+k$

Where $Y_{d}$ is the value of distortion at proportional period $X$ and $k$ is a constant.

Assuming that the intensity of the distortion is $\boldsymbol{I}$, the following applies;

$\mathrm{X}_{1}{ }^{1}+\mathrm{X}_{2}{ }^{1}+\mathrm{X}_{3}{ }^{1}+\ldots \mathrm{X}_{\mathrm{n}}{ }^{1}=\mathrm{K}$

$\mathrm{X}_{1}^{2}+\mathrm{X}_{2}^{2}+\mathrm{X}_{3}^{2}+\ldots \mathrm{X}_{\mathrm{n}}^{2}=\mathrm{L}$

$X_{1}^{3}+X_{2}^{3}+X_{3}^{3}+\ldots X_{n}^{3}=M$

$\mathrm{X}_{1}^{4}+\mathrm{X}_{2}^{4}+\mathrm{X}_{3}^{4}+\ldots \mathrm{X}_{\mathrm{n}}^{4}=\mathrm{N}$

Then

$a_{1} K+a_{2} L+a_{3} M+a_{4} N=I$

The above are used to find the parameters $a 1, a 2, a 3$ and $a 4$ as follows;

$\mathrm{k}=0$

$\mathrm{a}_{1}=0$

$\mathrm{a}_{2}=-\left(\mathrm{a}_{3}+\mathrm{a}_{4}\right)$

$\mathrm{a}_{3}=-2 \mathrm{a}_{4}$

$\mathrm{a}_{4}=\mathrm{I} /(\mathrm{N}-2 \mathrm{M}+2 \mathrm{~L})$

Therefore,

The value of the intensity is generated through $\mathrm{Y}$.

If the distortion is Retarding then the values for $\mathrm{Y}$ are multiplied by -1 .

The duration of the intensity is generated through $\mathrm{X}$. 
The position of the distortion is where the $2^{\text {nd }}$ derivative of the main curve is zero.

\section{Performance of the Mathematical Expression}

The above mathematical model is able to generate curves that comply with all general and specific characteristics of a project expenditure profile. The model is capable of exerting full control over the values of these variables. This flexibility is demonstrated in Figures 8 to 12 . For instance Figure 8 displays full control over the position of the peak on the time axis. Figure 9 depicts the same for the position of the peak on the value axis. In Figure 10 it is shown that the value of initial and end slopes could be manipulated without affecting the overall expenditure intensity. The role of parameter $d$, in the Control Module, for balancing the total project value, is shown in Figure 11. Figure 12 reflects the performance of the Kurtosis Module in controlling the value of Expenditure Intensity (the Kurtosis expression represents intensity from 0 to 1 , but when applied to a case, it is multiplied by the actual value of the intensity). 


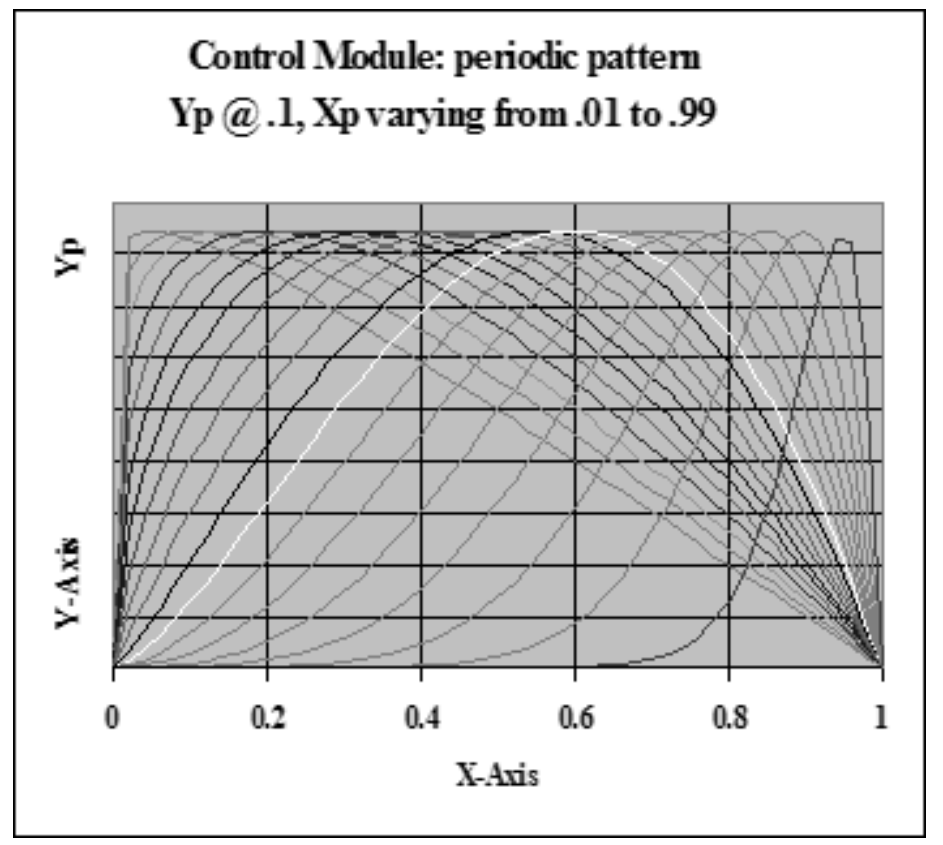

Figure 8, varying values of peak period

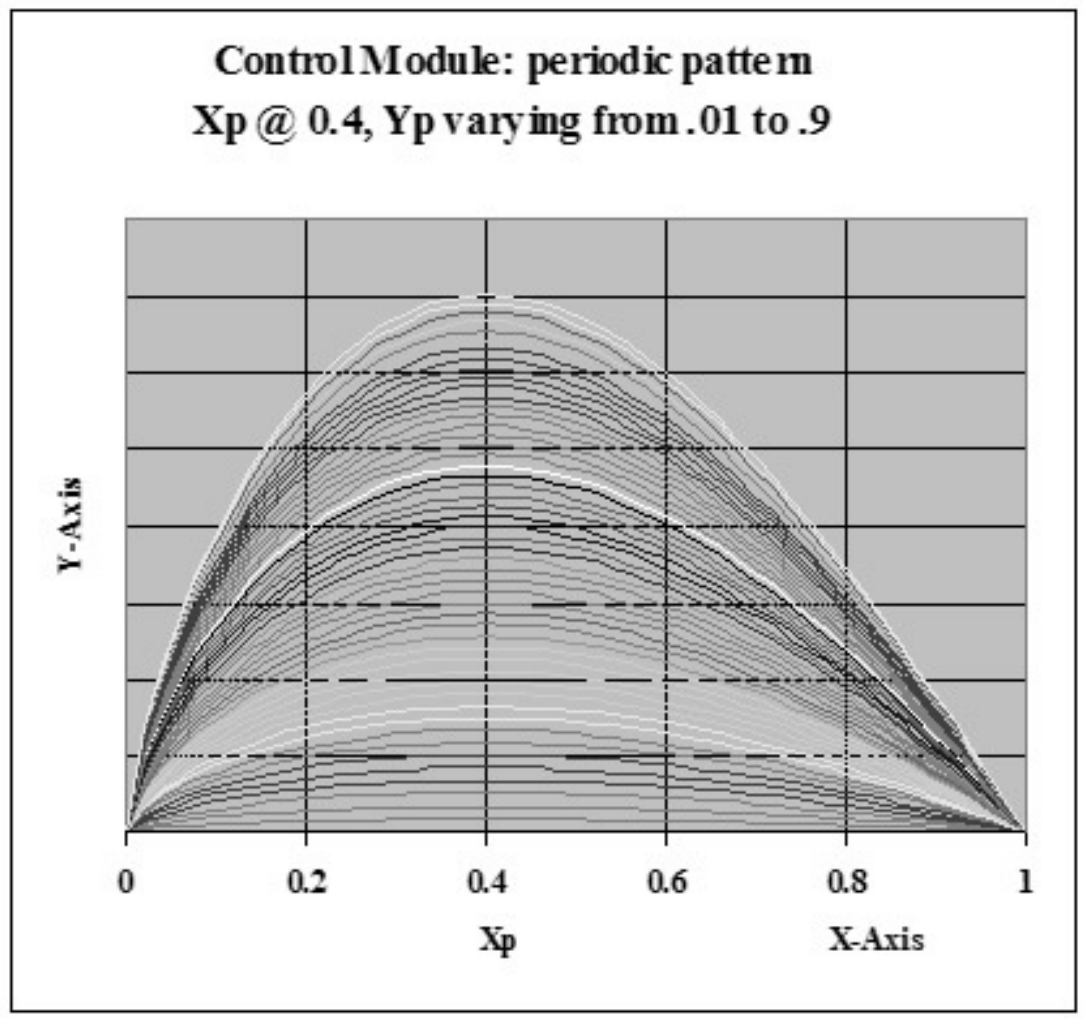

Figure 9, varying values of peak value 


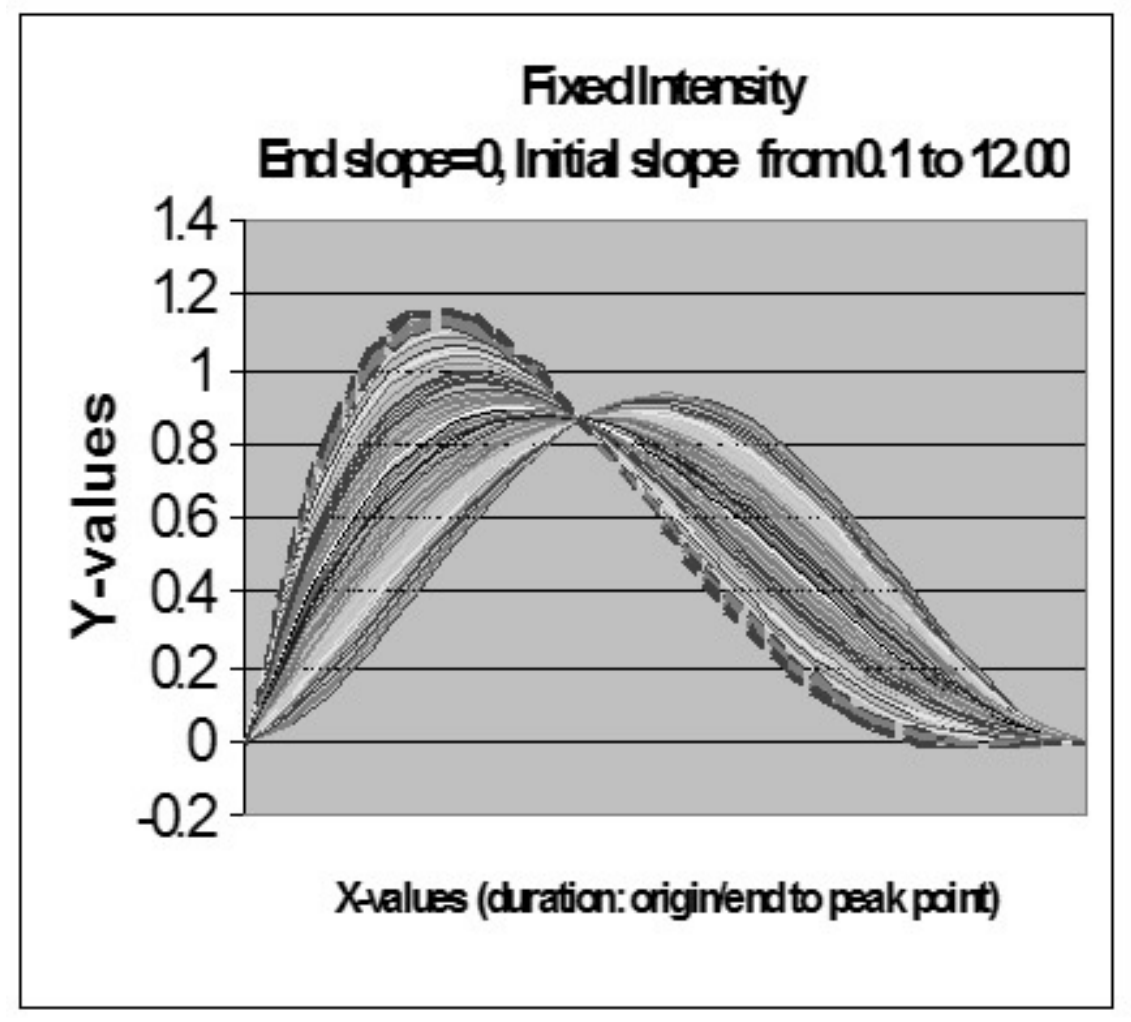

Figure 10, varying start \& end slope values

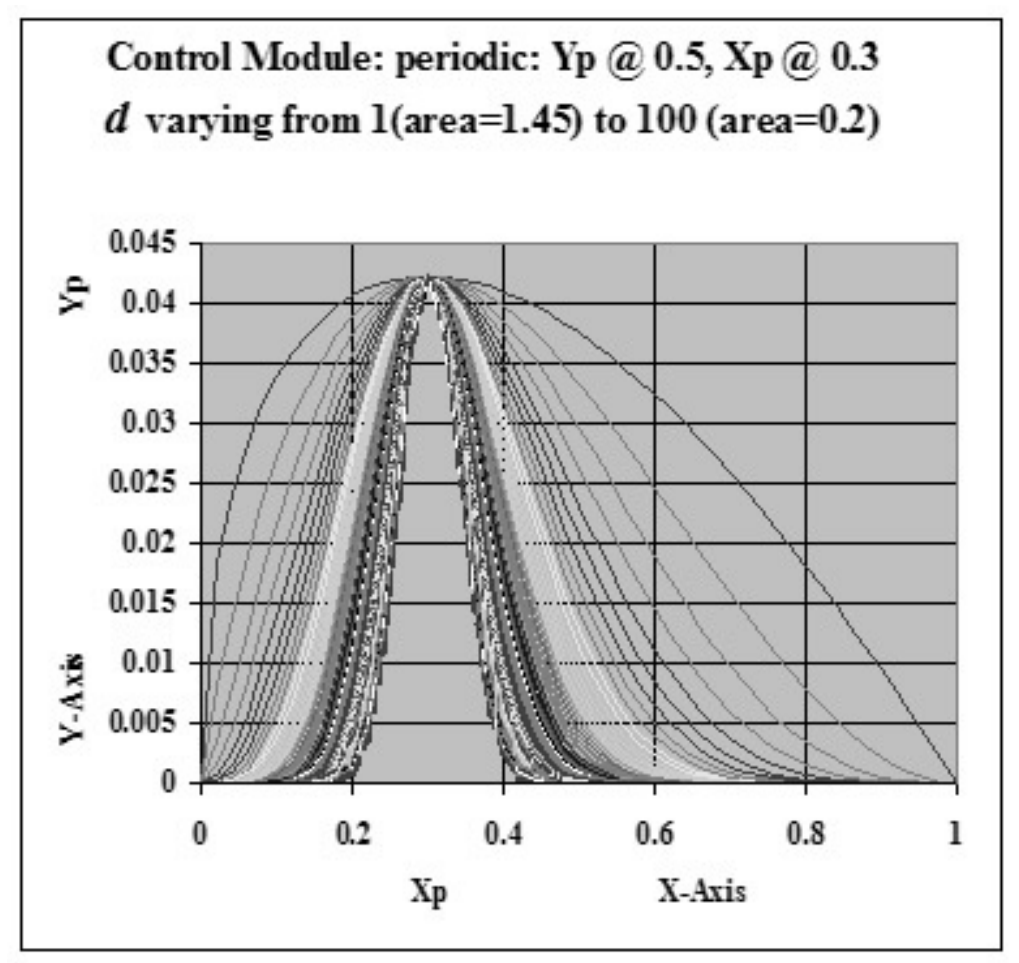

Figure 11, Overall balancing control 


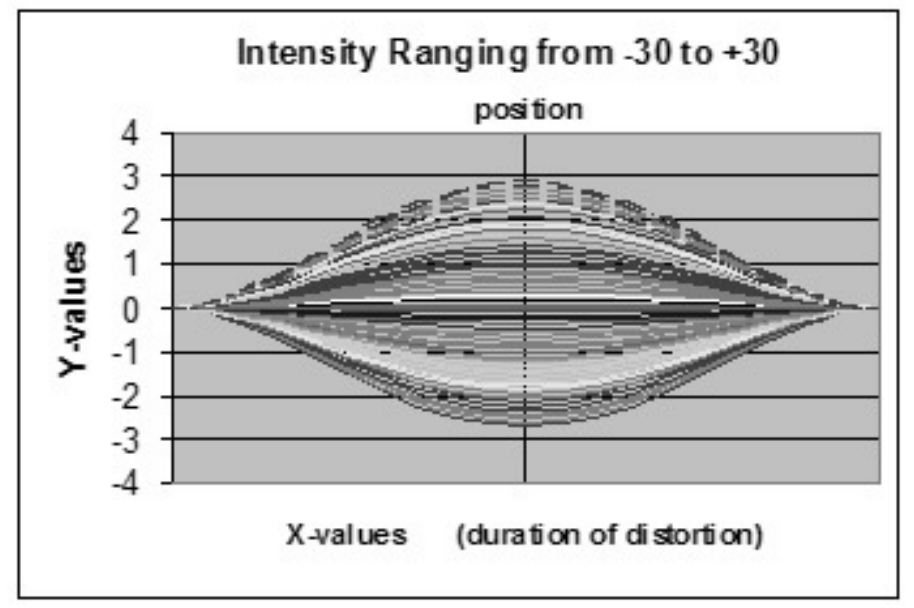

Figure 12, varying curve intensity

\section{DETERMINISTIC APPROACH TO FINANCIAL}

\section{MANAGEMENT}

The expression of lack of confidence in the predictive accuracy of financial models dates back to early years of methodological approach to forecasting (Jepson, 1969). Ultimately, forecasting is a crystal gazing exercise. It applies to areas where an accurate prediction cannot be obtained. Previous studies into the accuracy of expenditure forecasting at early stages have concluded that the level was less than acceptable. This has been suggested by researchers throughout the 1980s and 1990s (Skitmore, 1988, and Gunner and Betts, 1990). This raises the question as to whether the inability of the models to generate accurate forecast renders these methods useless and the very attempt of forecasting is futile. These issues have led some organisations to question the benefits of the use of forecasting models and others exercising managerial decisions to influence the cost performance (Ireland, 1985). On the other hand, 
there are contractors who are content with the use of their adopted model and expect their projects to conform to the forecast. To address these diversities, it is imperative to develop an understanding about the role of project cash flow and its relationship with financial management at both project and corporate levels. Normally, the forecast of project expenditure is produced at the estimating and tendering stages. The expenditure flow will then form the basis for forecasting project cash flow. This is primarily a project-based exercise, however, it directly contributes to the management of corporate finance. Due to this relationship, the management of corporate finance could potentially start by financial management at the project level. Lam et al. (2001) have highlighted the importance and complexity of multi-project cash flow decisions and suggested the use of a model that integrates the multi-objective linear programming and neural network. Kaka and Lewis (2003) also criticise the current methods of cash flow prediction and suggest that often corporate budgets do not include projects. They offer a model for cash flow forecasting at both individual projects and at a company level.

Considering the project as a financial entity allows reviewing it from a different perspective: the solitary role of the project is negated in favour of its contributory role as part of the organisation's corporate objectives (Navon, 1996). This way, a great deal of flexibility can be exercised at the project level. This is based on the supposition that, similar to other businesses, in construction everything can be negotiated between the parties. All standard forms and traditional practices can be 
revised if the parties (the client, contractor and sub-contractor) agree to negotiate a win-win solution. The practicality of the solution is based on the fact that, at any given time, the parties may have different priorities thus, the search for complementary rather than conflicting objectives is not always futile.

The process involved in the implementation of this approach is shown in Figure 13, and consists of the following stages.

1. Use the mathematical model to forecast the 'most likely cash flow'.

2. Exploit the general experience of the analyst to improve the forecast.

3. Use the specific knowledge of the analyst to refine the forecast.

4. Evaluate the position of the project in relation to corporate objectives to identify the 'preferred cash flow'.

5. Embark on negotiation with parties (client, contractor and sub-contractor) to achieve a win-win solution.

6. Synthesize the 'most likely cash flow' with the 'preferred cash flow' into 'compromised cash flow'.

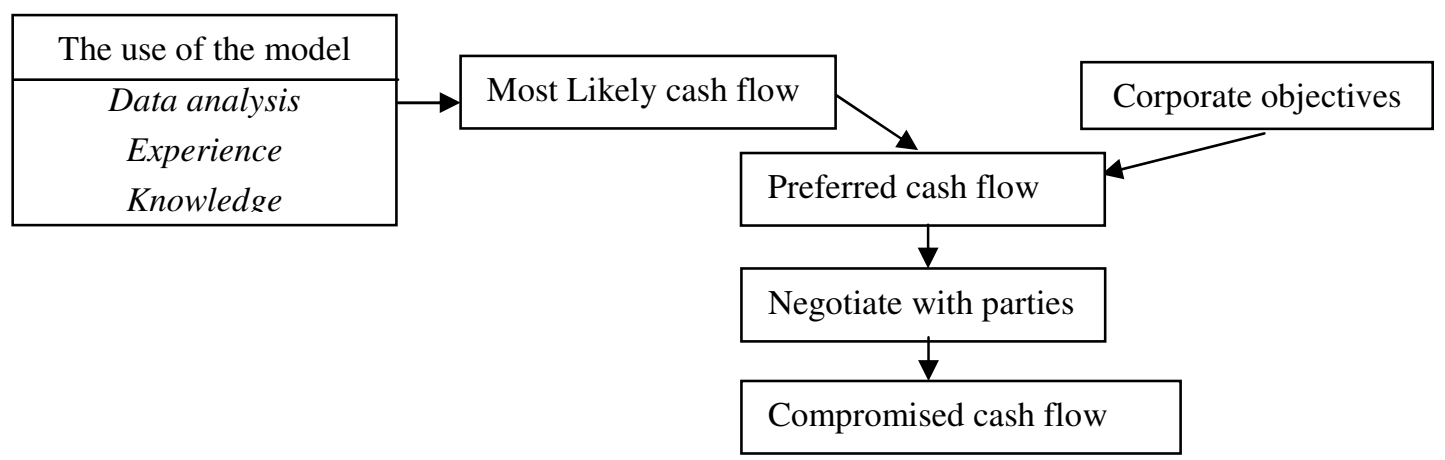

Figure 13. The structure of the approach 
The mathematical expression goes as far as generating the profile once the values of the profile-variables are specified. These values are determined by the nature of the project. As noted earlier, a series of estimating-models have been developed which, based on the nature of the project, determine the value of the profile-variables. For these variables to be estimated, the project needs to be defined in terms of the aforementioned Project-Characteristics (project type sub-type, operation, form, scope, structural properties, ground condition, height, access within the site, buildability and abnormal events). These project characteristics inherently impact on the configuration of the expenditure profile. However, the cash flow is also affected by the following project parameters which are incorporated into the Financial Model.

-Retention parameters

-Interest charge and Interest Gain applicable to each period

-Payment Interval (often monthly).

-Payment Delays: before the contractor receives first and subsequent payments.

-Front End Loading: the unwritten tactic to improve cash flow or cash returns.

-Contractor's Cost: methods of payments to sub-contractors and suppliers.

-Mark-up: as \% of the contractor's cost

-Cash Injection or Withdrawal: to or from the project.

-Project Start Date: has impact on cash flow profile (e.g. holidays \& weather). 


\section{A SCENARIO}

In this section the proposed approach to project financial management has been applied to the construction of a real new-build modern secondary school project, based on the traditional method of procurement. The value and the duration of the project are $£ 821 \mathrm{k}$ and 16 months respectively. However, the scenario has been fictitiously applied to demonstrate how to negotiate a win-win solution by manipulating project parameters and applying them to the forecasted cash flow. For this purpose, a prototype software has been developed and used to visually examine numerous scenarios that could be applied to any given project. In this example, the contractor wishes to avoid negative cash flow and the client is prepared to comply with some of contractor's requests for a reduced profit margin. In this example, the proposed model has already generated the forecast, based on which, the cash flow has been produced.

Initially, the project was based on a 5\% profit margin and the usual project terms applied: payments were to be received on a monthly valuation basis ( 45 days for the first payment), retention at 5\%, and no front-end loading was applied. Figure 14 shows the resulting forecast of project cash flow (the most likely cash flow) produced by the model. Despite the mark-up at $5 \%$, the net, maximum and real cash flows are all in the negative zone throughout the project. At the end of the project (practical completion) half of retention is released. There are no more payments for six months of defect liability period before the remaining half of retention is released. It takes 17 months before the cash flow turns into positive 
leading towards profit. But, there can be several reasons why the contractor may not desire this cash flow and undertake to manipulate it towards the 'preferred cash flow'.

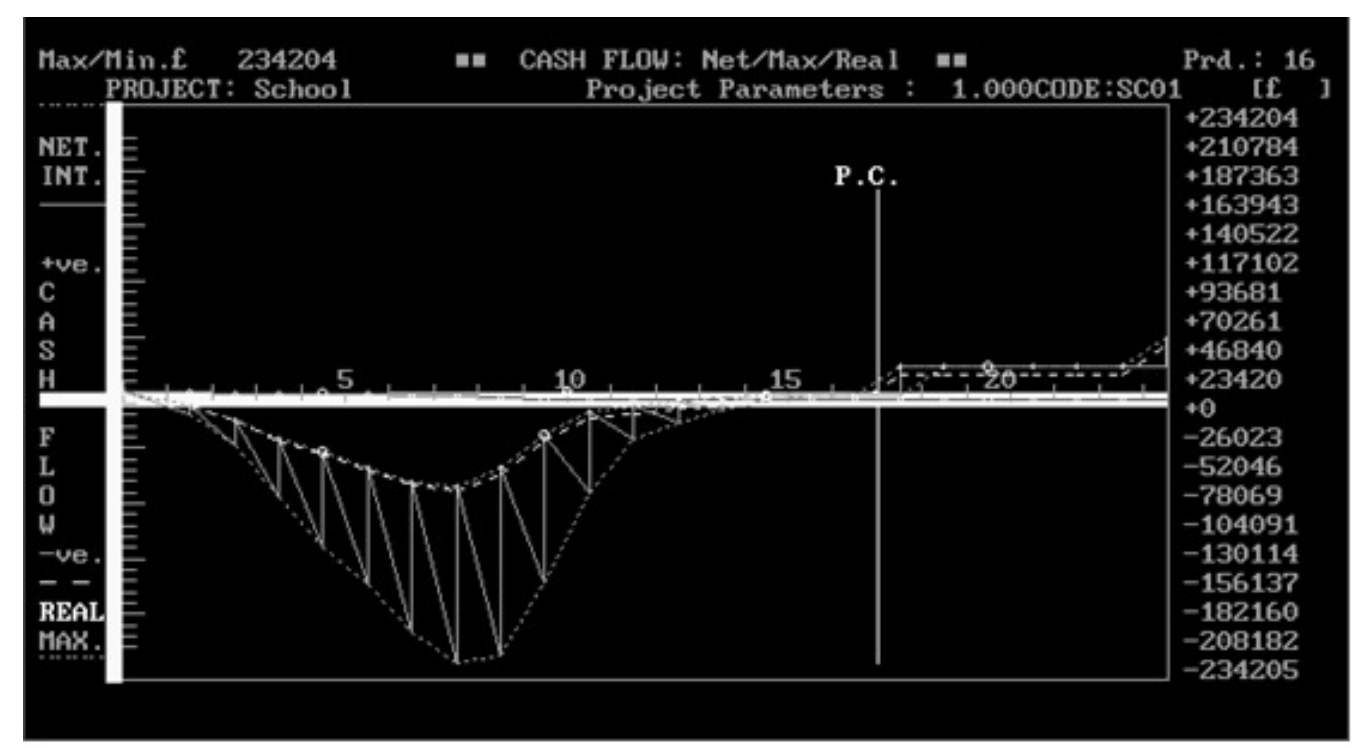

Figure 14. forecast of the 'actual cash flow' @ 5\% mark-up 


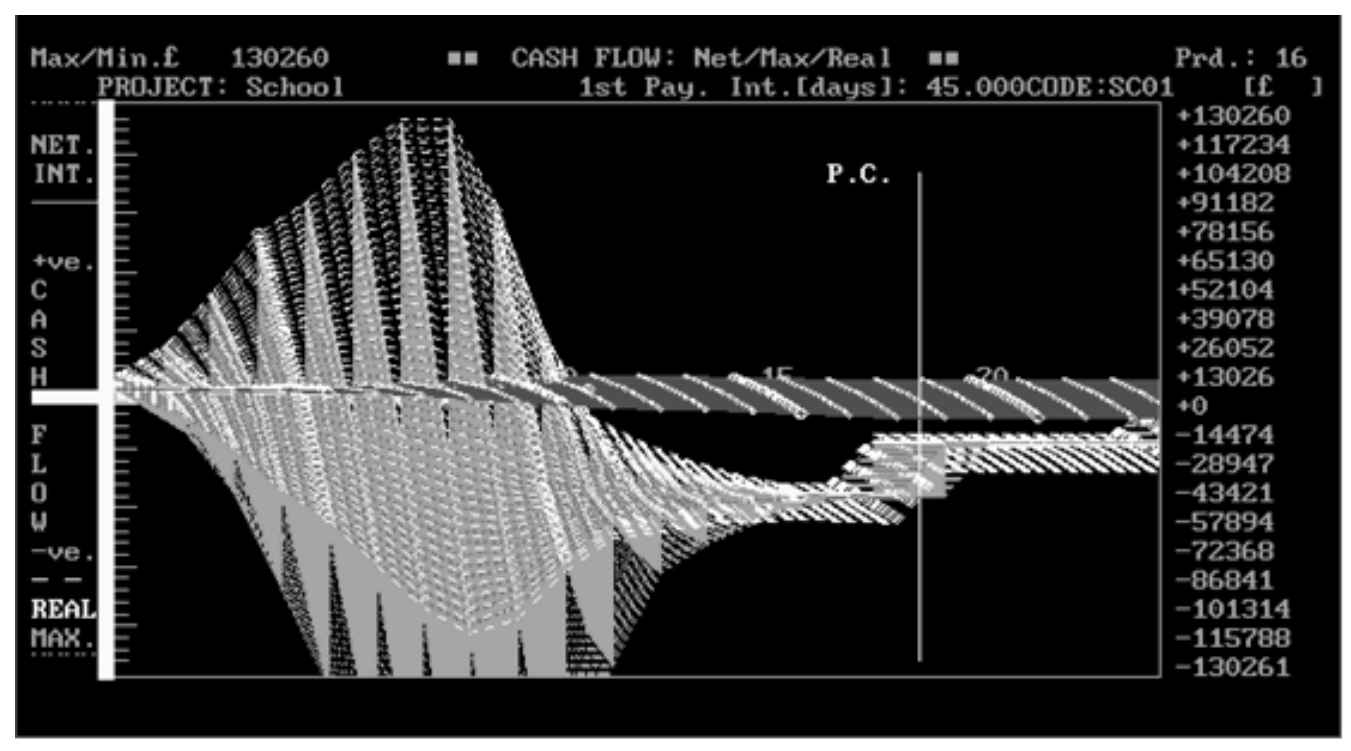

Figure 15. Cash flows: mark-up 5\%, first payment after 1 to 45 days

Typically, project cash flow is very much shaped by project operational progress, but there is a limit in the way project programme can be manipulated. Alternative optimising solutions include the work by Zhang et al. (2006) who adopt an innovative approach to the use of Particle Swarm Optimisation method, which is typically used to simulate social behaviours, to solve a multimode resource-constrained project Schelling problem and help with the analysis and planning of construction scheduling. Also, there are ways by which project policies and strategies could be examined to impact on its performance. For instance, Nguyen and Ogunlana (2005) propose a dynamic simulation model that could be used by the contractor to simulate and evaluate different strategies for project performance before the implementation. 
In this section the management of project financial behaviour is carried out through the manipulation of project parameters such as profit margin, and payment methods and intervals. However, this cannot be carried out unilaterally in isolation from other parties and any such decisions may require negotiation and possibly compromises. Prior to the negotiation the contractor could visually examine various alternative solutions and identify the boundary decisions. This will enable them to exercise a degree of control during the negotiation. In this scenario, the contractor contemplates experimenting with zero profit margin in return for the client's consent to reduce the delay in making the first payment. At $0 \%$ mark-up, Figure 15 shows a range of possible cash flow profiles, as the delay in receiving the first payment changes from 1 to 45 days. Figure 16, on the other hand, examines the role of partial delay in payment to sub-contractors. These figures show a wide range of possible solutions. These solutions are generated in steps whereby the analyst could view and examine the impact of changing the values of mark-up and the delay in payments to subcontractors. 


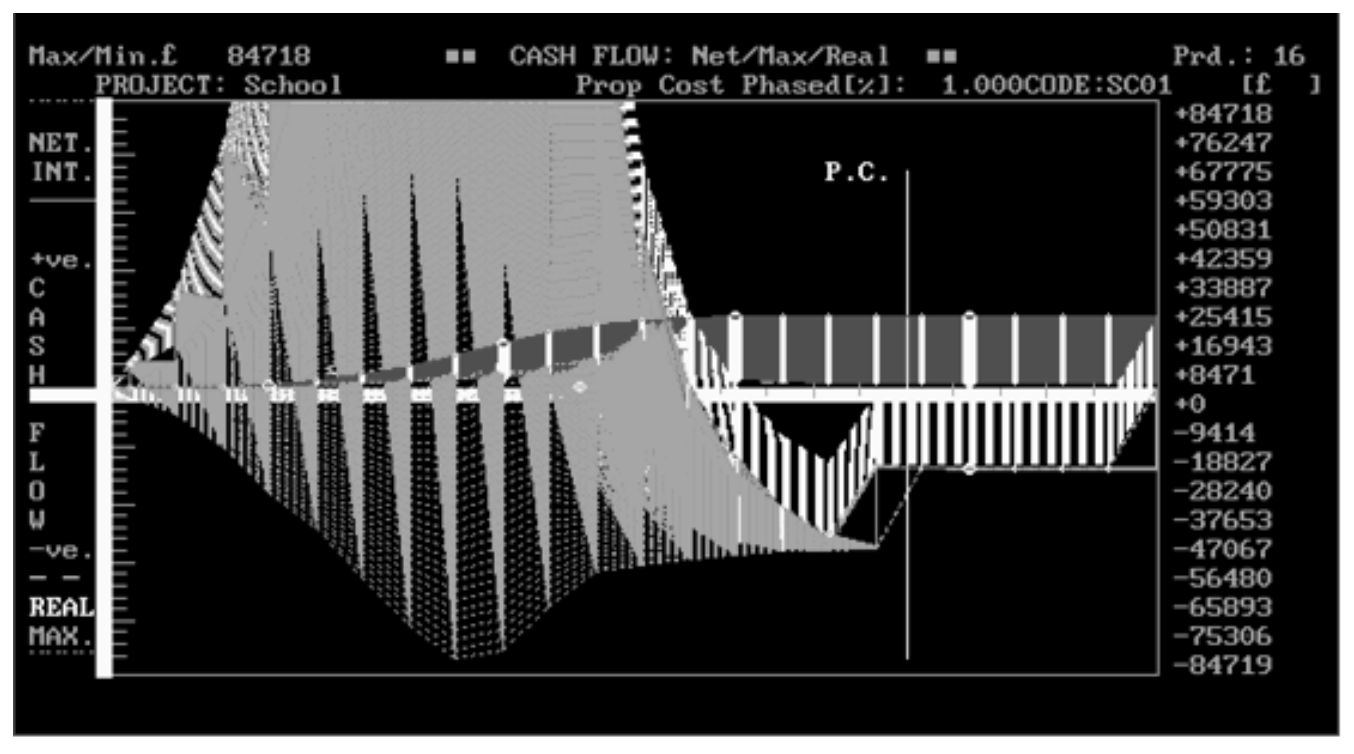

Figure 16. Cash flow; mark-up 0\%, delay $1 \%$ to $100 \%$ of payments to S/Cs by 2 months

The visual and numerical examination of parameters could result in the identification of an envelope of acceptable solutions one of which is considered here. Figure 17, represents the cash flow for the contractor who has accepted to undertake the work at $0.00 \%$ profit margin as a compromise for client's acceptance to deposit the first payment after 10 days rather than the usual 45 days delay, with the subsequent payments made on the usual monthly basis. The contractor has also assured the sub-contractors of an immediate payment of $75 \%$ of their invoices with the remaining $25 \%$ paid after 2 months. All other terms such as retention, defect liability period and monthly payments remain as before. 


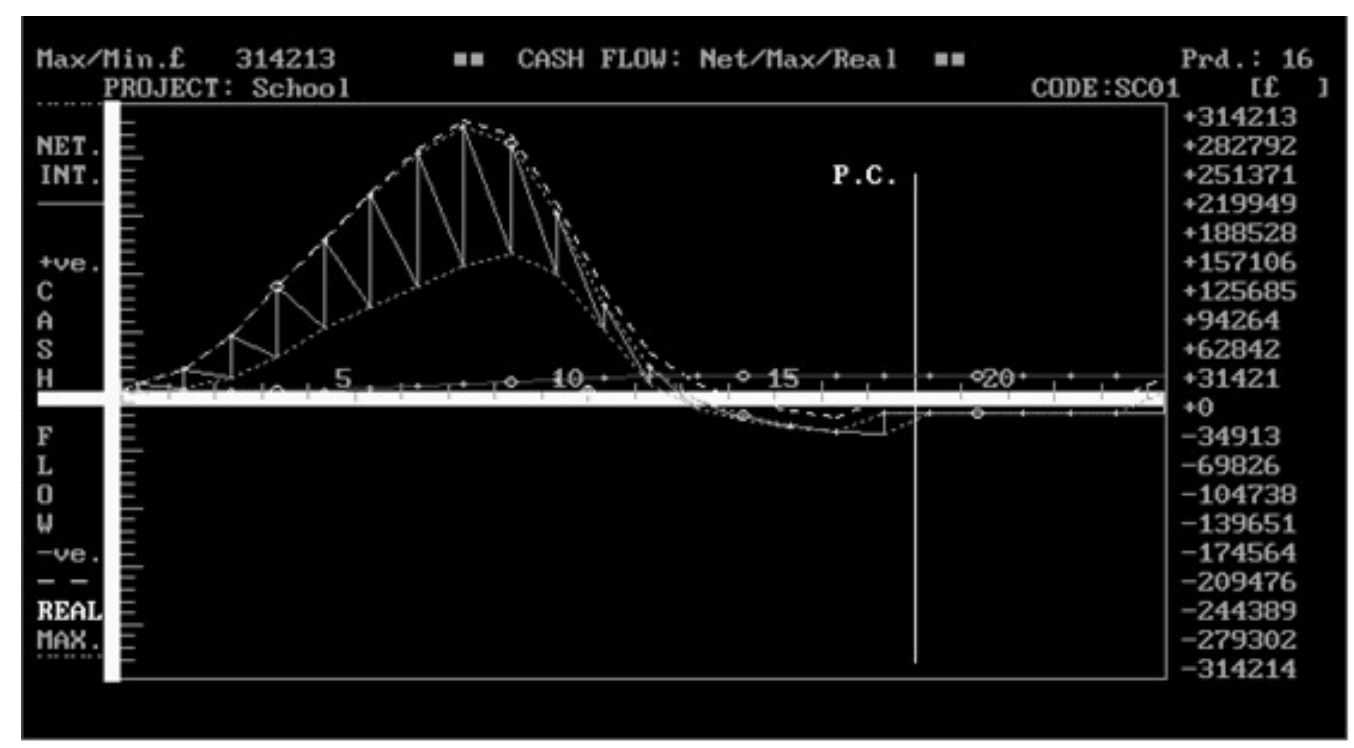

Figure 17. 'preferred cash flow', achieved at $0 \%$ mark-up

This scenario demonstrates that the parties can negotiate a set of complementary objectives for their mutual benefits. On this occasion, while the client enjoys a free service form the contractor (zero mark-up) they also share the contractor's consolation for having a healthy cash flow throughout the project. Also, the subcontractors welcome the certainty of an agreed payment regime by the contractor and that a part of it is paid immediately.

\section{CONCLUSIONS}

The paper highlights the importance of cash flow forecasting and management and discusses a number forecasting models for project expenditure pattern. The use of curve-geometry for the examination of the characteristics of typical 
profiles allowed defining the profile in terms of a number of variables associated with the shape of the profile.

The paper introduces the overall model, which consists of a mathematical expression and a series of estimating models that, for a given project definition, identify the value of shape-variables. The separation of data form the mathematical expression enables unlimited expansion of the application of the model to all possible scenarios without the need to restructure the mathematical expression. The paper describes the details of the proposed component-based mathematical component and demonstrates the features that enable these components to possess the flexibility that is required of the model. These include the development of a new exponentially-based expression and its amalgamation with two new $4^{\text {th }}$ degree polynomial expressions. Collectively, these modules accommodate the variables relating to projects, the impact of abnormalities on project cash flow and the ability of users to exploit their experience and knowledge to refine the forecast.

The paper advocates a new attitude towards project financial management and a new approach to the use of forecasting models. It has been asserted that the use of financial forecasting models is essential in determining the 'most likely cash flow' of the project. But, it was reiterated that efforts must also be composed to configure the financial aspects of the project in the direction of corporate objectives of the organisation. This leads to the identification of the 'preferred cash flow'. It has been noted that for the organisation to achieve the desired cash flow, they should assume a more business view of the project. There 
are numerous ways by which project parameters can be manipulated to produce alternative cash flows. The paper introduced the model as an effective visual tool for simultaneous examination of several scenarios. This form of support system allows the contractor to align its projects with its corporate objectives and in doing so attempt to match its priorities with those of other parties.

A scenario was used to demonstrate the process by which project cash flow is produced, refined and then rearranged to reflect the broader objectives of the contractor. Accordingly, with $0.00 \%$ mark-up, the contractor managed to negotiate a win-win solution with the client and sub-contractors, and yet secure a healthy cash flow and profit at the end of the project. In preparation for negotiation, each party could use this model to secure an advantage. Alternatively, in a collaborative environment like project partnering all parties could use the model to agree on mutually beneficial objectives.

\section{REFERENCES}

Ashley, D. B., and Teicholz, P. M. (1977) "Pre-Estimate Cash Flow Analysis", Journal of Constr. Div, ASCE, 102 (3), 369-379, USA.

Allsop, P. (1980) Cash Flow and Resource Aggregation from Estimator's Data, MSc in Construction Management Project Report, Loughborough University of Technology, UK.

Balkau, B. J. (1975) A Financial Model for Public Works Programmes, Paper to National ASOR Conference Sydney, August 1975, 25-27 
Berny, J. and Howes, R. (1982) Project management control using real time budgeting and forecasting, Construction Papers no 2.

Bromilow, F. J. and Henderson, J. A. (1974) Procedures for Reckoning the Performance of Building Contracts, $2^{\text {nd }}$ ed, CSTRO, Division of Building Research Special Report, Australia

Boussabaine, A. H., Thomas, R. and Elhag, T. (1999) Modelling cost-flow forecasting for water pipeline projects using neural network, Engineering, Construction and Architectural Management, 6/3, 213 - 224. UK.

Cooke B. and Jepson W. B. (1979) Cost and financial control for construction firms, Macmillan Education ltd.

Drake, B. E. (1978) A Mathematical Model for Expenditure Forecasting Post Contract. Proceedings of the second International Symposium on Organisation and Management of Construction, Technion Israel Institute of Technology, Haifa, Israel, 163-183.

Egan, Sir J. (1998) Rethinking Construction, DETR, London.

Flanagan, R. and Norman, G. (1983) The accuracy and monitoring of quantity surveyors' price forecasting for building work, Construction Management and Economics, vol 1, no 2, E\&FN Spon Ltd, UK.

Gompertz, B. (1825), On the nature of the function expressive of the law of human mortality, Philosophical Transactions of the Royal Society, Vol. Xxxvi, 513-585. 
Gunner, J. and Betts, M. (1990), Price forecasting performance by design team consultants in the Pacific Rim, CIB W-55/65 Symposium, Value in Building Economics and Construction Management, vol 3, Australia.

Hardy, J. V. (1970) Cash Flow Forecasting for the Construction Industry, MSc report, Department of Civil Engineering, Loughborough University of Technology.

Harris, F.and McCaffer, R. (1995) Modern Construction Management, fourth ed., Cambridge. Blackwell Science, UK.

Hudson, K. N. (1978) DHSS Expenditure forecasting method. Chartered Surveyor, Building and Quantity Surveyor Quarterly, 5, 1978.

Ireland, V. (1985) The role of managerial actions in the cost performance of high rise commercial building, Construction Management and Economics, 3, 59-87, E\&FN Spon Ltd, UK

Jepson, W.B. (1969) Financial Control of Construction and Reducing the Element of Risk, Contract Journal, 24, April, 8620864

Kaka, A. P., and Price, A. D. F. (1991) Net Cash Flow Models - Are They Reliable? Construction Management and Economics, 9, 291 -308, E\&FN Spon Ltd, UK.

Kaka, A. P., and Price, A. D. F. (1993) Modelling Standard Cost Commitment Curves for Contractors' Cash Flow forecasting, Construction Management and Economics, 11, 271-283, E\&FN Spon Ltd, UK. 
Kaka, A P., and Khosrowshahi, F. (1996) Effects Of Different Procurement Routes On Contractors' Cash Flow, Engineering, Construction and Architectural Management, 3, 133-145, UK.

Kaka, A. P. and Evans, R. C. (1998) Analysis of the accuracy of standard/average value curves using food retail building projects as case studies, Engineering, Construction and Architectural Management, 5, 58-67, UK.

Kaka, A P and Lewis, J (2003) Development of a company-level dynamic cash flow forecasting model (DYCAFF). Construction Management and Economics, 21(7), 693-705.

Keller, A. Z., Green, F., and Ashrafi, (1984) Forecasting Expenditure on Capital Projects, Long Range Planning, vol. 17, No. 4, 110-114

Kenley R. and Wilson, I. D. (1986) A Construction Project Cash Flow Model An Idiographic Approach, Construction Management and Economics, 4, 213232, E\&FN Spon Ltd, UK.

Khosrowshahi, F. (1996) Value profile analysis of construction projects, Journal of Financial Management of Property and Construction, vol 1, no 1, $55-77$, UK.

Khosrowshahi, F. and Alani, A. (1993) A Model for Smoothing Time Series Data in Construction, Construction Management and Economics, July 2003, $21,483-494$

Lam, K C, Hu, T, Cheung, S O, Yuen, R K K and Deng, Z M (2001) Multiproject cash flow optimization: non-inferior solution through neuro- 
multiobjective algorithm. Engineering, Construction and Architectural Management, 8(2), 130-44.

Lowe, J. G. and Moussa, N. and Lowe, H. C. (1993) Cash flow management: an expert system for the construction client. Journal of Applied Expert Systems, 1(2): 134-152.

Navon, R. (1996) Company-Level Cash Flow Management, Journal of Construction Engineering and Management, March, 22-29.

Neil, J.M. (1982) Construction Cost Estimating for Project Control, PreticeHall International.

Nguyen, L. D. and Ogunlana, S. O. (2005) Modelling the Dynamics of an Infrastructure Project, Computer-Aided Civil and Infrastructure Engineering 20 pp265-279

Oliver, J.C. (1984) Modelling Cash Flow Projections using a Standard Micro Computer Spreadsheet Programme, MSc Project in Construction Management, Loughborough University of Technology, UK.

Skitmore, M. (1988) Factors affecting the accuracy of engineers' estimates, Cost Engineering, vol 30, no 10, AACE, USA.

Singh, S. and Woon, P.W. (1984) Cash Flow Trends for High Rise Building Projects. In organising and managing construction, in Proceedings of the $4^{\text {th }}$ International Symposium on Organisation and Management of Construction, University of Waterloo, Canada.

Stone, R. (1980), Sigmoids, Bulletin of Applied Statistics, 7(1), pp. 59 - 119. 
Tucker, S N (1986) Formulating construction cash-flow curves using a reliability theory analogy. Construction Management and Economics, 4(3), 179-88.

Zhang1, H., Tam, C. M. and Li, H., (2006) Multimode Project Scheduling Based on Particle Swarm Optimization, Computer-Aided Civil and Infrastructure Engineering Volume 21 issue 2 Page 93 - February 2006 